\title{
Glukosaminbruk
}

\section{reduserer ikke behovet for analgetika}

\begin{abstract}
Sammendrag
Bakgrunn. Glukosamin har siden 2004 vært tilgjengelig på resept for symptomatisk behandling av mild til moderat artrose. Formålet med denne studien var å kartlegge bruksmønsteret og pasientenes samtidige bruk av andre smertestillende legemidler samt forskrivers spesialitet.
\end{abstract}

\section{Materiale og metode. Det ble gjort datauttrekk fra Reseptregisteret for årene 2004, 2005 og 2006 for glukosa- minresepter innløst ved norske apote- ker. I samme periode og for de samme pasientene registrerte vi resepter på kodeinholdige analgetika og ikke- steroide antiinflammatoriske midler (NSAID-preparater) refundert på grunn av artrose.}

Resultater. Totalt 91107 personer løste i treårsperioden inn 297588 glukosaminresepter til en samlet kostnad av vel 70 millioner kroner. $86 \%$ av pasientene var over 50 år, og det var $69 \%$ kvinner. Av leger med kjent spesialitet sto spesialister i allmennmedi$\sin$ for $84 \%$ av forskrivningene. $33 \%$ av pasientene innløste glukosaminresepter hvert av de tre årene. Av dem som brukte glukosamin jevnlig, fikk $19 \%$ ordinert NSAID-preparater for artrose, og $22 \%$ brukte kodeinholdige analgetika. De som begynte med glukosamin, reduserte ikke forbruket av kodeinholdige analgetika. Når det gjelder NSAIDpreparater, var det tvert imot en positiv korrelasjon mellom forbruket av glukosamin og forbruket av NSAID-preparater

Fortolkning. Bruk av glukosamin fører ikke til redusert bruk av andre smertestillende midler. Dette kan tyde på manglende klinisk effekt av midlet.

\section{Hilde Moseby Berge*}

hilde.moseby.berge@nih.no

Allmennmedisinsk forskningsenhet

Seksjon for allmennmedisin

Institutt for helse og samfunn

Universitetet i Oslo

Postboks 1130 Blindern

0318 Oslo

og

Hjelp24 NIMI

Postboks 3843 Ullevål Stadion 0805 Oslo

\section{Svein Gjelstad}

Allmennmedisinsk forskningsenhet

Seksjon for allmennmedisin

Institutt for helse og samfunn

Universitetet i Oslo

\section{Kari Furu}

Avdeling for legemiddelepidemiologi

Divisjon for epidemiologi

Nasjonalt folkehelseinstitutt

\section{Jørund Straand}

Allmennmedisinsk forskningsenhet

Seksjon for allmennmedisin

Institutt for helse og samfunn

Universitetet i Oslo

* Nåværende adresse:

Norges idrettshøgskole

Postboks 4014 Ullevål Stadion

0806 Oslo

Artrose er den vanligste leddsykdommen og representerer et stort og økende helseproblem som kan gi betydelig funksjonssvikt og redusert livskvalitet $(1,2)$. Bak tilstanden kan det ligge både arvelige, biokjemiske og biomekaniske forhold $(3,4)$.

Pasienter med symptomgivende artrose er først og fremst plaget av smerter og redusert funksjon. Effektene av ikke-farmakologisk og ikke-kirurgisk behandling av hofteleddsartrose er mangelfullt dokumentert (5). For kneleddsartrose kan fysikalsk behandling, spesielt trening, ha gunstig effekt når det gjelder smerter og funksjon (6). Symptomlindrende legemidler, i hovedsak ikke-steroide antiinflammatoriske midler (NSAIDpreparater), brukes ofte ved artrose. I en nyere metaanalyse er det imidlertid slått fast at slike preparater bare har beskjeden effekt på kroniske smerter ved kneleddsartrose (7).

I 2004 ble glukosamin godkjent som legemiddel til behandling av artrose $\mathrm{i}$ hofter og knær i Norge. Studier har vist at midlet kan ha gunstig effekt på smerter, leddbevegelighet og brusknedbrytning $(8,9)$. Tidligere studier har vist at det var signifikant mindre leddspaltehøydereduksjon etter tre års be- handling med glukosaminsulfat enn etter bruk av placebo $(10,11)$.

I en stor amerikansk undersøkelse fra 2006 ble 1583 pasienter med kneleddsartrose randomisert til ett av fem ulike behandlingsregimer (12). Konklusjonen var at verken glukosamin alene eller glukosamin i kombinasjon med kondroitinsulfat reduserte smertene effektivt. Etter to års oppfølging av 357 av pasientene var det ingen signifikant forskjell i brusknedbrytning mellom dem som hadde fått placebo og dem som hadde fått de andre behandlingsalternativene (13). Studien er senere blitt kritisert fordi det ikke ble benyttet glukosaminsulfat, ettersom det muligens er sulfatdelen som har den viktigste strukturmodifiserende effekten ved artrose $(14,15)$. Mekanismene for hvordan glukosamin eventuelt virker ved denne tilstanden er ikke dokumentert (16).

Mens glukosamin i Norge er et reseptbelagt legemiddel, kan det i for eksempel Sverige fås uten resept eller som kosttilskudd. Midlet selges også via Internett. I Norge kostet i 2006 ett års forbruk av glukosamin rundt 1250 kroner, som ikke ble refundert gjennom blåreseptordningen. Hvis midlet virkelig motvirket utviklingen av artrose, ville det kunne bety mye for mange. Hvis det derimot ikke virker, får pasientene unødvendig behandling og bortkastede utgifter.

Statens legemiddelverk anbefaler at artrosepasienter kan forsøke glukosamin i seks uker, men at behandlingen bør avsluttes dersom man i løpet av denne tiden ikke opplever merkbar effekt (17). I Sverige har en forsøksperiode på 2-3 måneder vært anbefalt (18). I praksis er det ikke enkelt å evaluere effekten av glukosamin - fordi symptomene ved artrose ofte varierer over tid. Dersom glukosamin gis i kombinasjon med andre midler, tre-

\section{Hovedbudskap}

- Mer enn 90000 pasienter løste inn resept på et glukosaminpreparat i tidsrommet 2004-06.

- Fire av ti hentet ut glukosamin fra apotek bare én gang, halvparten brukte glukosamin i mer enn ett år

- Økt bruk av glukosamin er assosiert med økende bruk av NSAID-preparater

- Bruk av glukosamin fører ikke til redusert forbruk av kodeinholdige analgetika 
Tabell 1 Bruken av glukosamin fra 1.1. 2004 til 31.12. 2006 samt ettårsprevalens i ulike aldersgrupper angitt i antall personer med minst én glukosaminresept per 1000 innbyggere per år

\begin{tabular}{|lccc|}
\hline & 2004 & 2005 & 2006 \\
\hline Antall resepter & 21571 & 120456 & 155531 \\
\hline Antall pasienter & 12260 & 53027 & 59460 \\
\hline Prevalens per 1000 innbyggere & & & \\
\hline$<40$ r & 0,5 & 2,3 & 2,4 \\
\hline $40-49$ år & 1,8 & 7,2 & 11,9 \\
\hline $50-59$ år & 5,2 & 21,3 & 22,7 \\
\hline $60-69 a ̊ r$ & 8,6 & 35,9 & 39,8 \\
\hline $70-79 a ̊ r$ & 8,6 & 39,3 & 45,3 \\
\hline $80-89 a ̊ r$ & 5,5 & 28,7 & 33,2 \\
\hline$\geq 90 a ̊ r$ & 2,1 & 11,9 & 14,4 \\
\hline
\end{tabular}

ning eller fysikalsk behandling, er det vanskelig å avgjøre hva det er som virker.

Vi kjenner ikke til tidligere studier der man har undersøkt hvorvidt artrosepasienter som begynner med glukosamin, etter hvert kan redusere forbruket av andre smertestillende midler. Det ville i så fall vært et indirekte tegn på klinisk effekt, noe som hadde vært gunstig - siden glukosamin har få bivirkninger (17).

Formålet med denne studien var å karakterisere glukosaminbrukerne ut fra alder, kjønn, glukosaminbruksprofil, forskrivende leges spesialitet og pasientenes samtidige bruk av NSAID-preparater (refundert for artrosesykdom) og/eller bruk av kodeinholdige analgetika. I september 2004 ble koksi- bet rofekoksib (Vioxx) trukket fra markedet, og i mai 2005 ble celekoksib (Celebra) fjernet fra blåreseptlisten. Vi ønsket derfor også å undersøke i hvilken grad glukosamin ble en erstatning for disse koksibene.

\section{Materiale og metode}

Reseptregisteret inneholder informasjon om alle utleveringer av reseptpliktige legemidler fra norske apoteker fra og med 1. januar 2004 (19). Identiteten til pasienter og forskrivere er kryptert (pseudonymisering), men likevel personentydig, slik at det er mulig å følge enkeltpersoners legemiddelbruk over tid. Reseptregisteret oppgir utleverte mengder av legemidlet $\mathrm{i}$ form av definerte døgndoser (DDD), der 1 DDD vanligvis

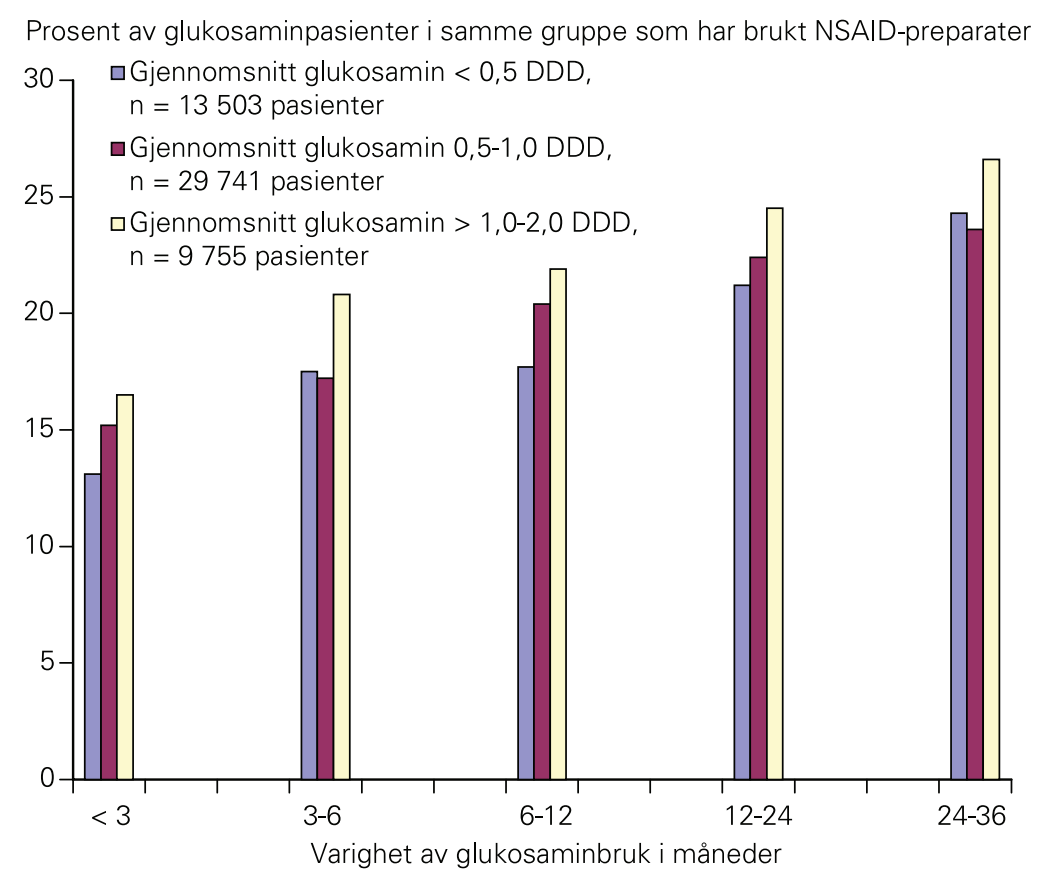

Figur 1 Sammenhengen mellom bruk av glukosamin og NSAID-preparater. Forbruket av glukosamin er gruppert etter gjennomsnitt av definerte døgndoser (DDD) og varighet i måneder. Bruken av NSAID-preparater $i$ de ulike gruppene er angitt i prosent

motsvarer døgndosen til en voksen person for hovedindikasjonen av midlet. For glukosamin motsvarer 1 DDD 1,5 gram. Reseptregisteret har opplysninger om forskrivers spesialitet. Leger uten oppnådd spesialitet kategoriseres som «andre».

Dataene i denne studien omfatter alle som fikk minst én glukosaminresept (ATC-kode M01A X05) i perioden 1.1. 2004-31.12. 2006. Mange av dem som fikk utlevert glukosamin, fikk i samme tidsrom ordinert andre smertestillende legemidler som ble med i uttrekket: NSAID-preparater og koksiber refundert etter blåreseptforskriftens punkt 35 (alvorlig symptomgivende koks- og gonartrose) og kodeinholdige analgetika. 490 glukosaminresepter utskrevet av veterinærer eller tannleger ble ekskludert fra analysene.

Datauttrekket ble gjort om til analysefiler i statistikkprogrammet SPSS slik at hver enkelt ordinasjon representerer et tilfelle (en case) med tilhørende opplysninger om blant annet innløsningsdato, antall definerte døgndoser og apotekets utsalgspris (AUP). Der en pasient hentet ut samme medikament flere ganger, har vi beregnet gjennomsnittlig DDD ved å dividere antallet ved første ordinering med antall dager til neste ordinering. Akkumulerte dager for bruk er antall dager fra første ordinering til beregnet seponering etter siste resept. Et tilfelle på ordineringsnivå ble deretter restrukturert til pasientnivå for å få hver pasient representert med én variabel for hvert legemiddel med korresponderende variabler for gjennomsnittlig DDD, antall ordineringer, akkumulerte DDD og akkumulerte dager for bruk.

For å kunne undersøke om økende forbruk av glukosamin førte til endring i bruken av andre smertestillende midler, delte vi forbruket av glukosamin i tre grupper basert på gjennomsnittlig antall definerte døgndoser $(<0,5$ DDD, 0,5-1 DDD og $>1,0-2,0$ DDD) og akkumulerte dager ved minst to resepter i perioden. De tre brukergruppene ble sammenliknet ved hjelp av logistisk regresjonsanalyse med henblikk på samtidig bruk av NSAID-preparater eller kodeinholdige analgetika $\mathrm{i}$ minst tre måneder $\mathrm{i}$ perioden.

\section{Resultater}

I løpet av treårsperioden fikk 91107 pasienter løst inn til sammen 297558 resepter på glukosamin (tab 1). Rundt halvparten av dem som fikk glukosamin for første gang i henholdsvis $2004 \operatorname{og} 2005$, fikk fortsatt midlet året etter. En tredel av dem som fikk glukosamin i 2004, innløste resepter i alle de tre årene. Prevalensen av glukosaminbruk var høyest i aldersgruppen 70-79 år (tab 1), og $69 \%$ av brukerne var kvinner. $41 \%$ av pasientene hentet bare ut én glukosaminresept. Totalt DDD-antall per ordinasjon var i gjennomsnitt 52, det vil si at reseptene passet med snaut to måneders forbruk.

Glukosamin ble solgt via apotek for 70126674 kroner fra 1. januar 2004 til 31. 
desember 2006. Gjennomsnittssum per resept var 236 kroner.

\section{Samtidig bruk}

av andre smertestillende midler

$39 \%$ (35 829 personer) av dem som fikk resept på glukosamin, fikk også skrevet ut legemidler refundert etter $\S 9$, punkt 35 (artrose). Av de 52999 pasientene som fikk mer enn én glukosaminresept i perioden, brukte 10271 (19,4\%) også NSAID-preparater i minst tre måneder i samme tidsrom, i gjennomsnitt i 482 dager med 0,64 DDD per dag. Tilsvarende hadde 11409 brukt kodeinholdige analgetika i minst tre måneder, i gjennomsnitt i 641 dager med 0,22 DDD per dag.

Det var en statistisk signifikant sammenheng mellom økende forbruk av glukosamin og NSAID-preparater $(\mathrm{p}<0,001$, test for trend) (fig 1). Det var en svak sammenheng mellom lav glukosamindose over tid og bruk av kodeinholdige analgetika, $\mathrm{p}=0,02$ for trend og oddsratio $1,047 \quad(95 \% \quad \mathrm{KI}$ 1,007-1,088). Det var ingen signifikant sammenheng mellom økende forbruk av glukosamin (daglig forbruk på henholdsvis $<0,5$ DDD, 0,5-1,0 DDD og > 1,0-2,0 DDD) og bruk av kodeinholdige analgetika ( $p$-verdier henholdsvis $0,98,0,31$ og 0,45 ).

\section{Hva kom etter koksibene?}

I september 2004 ble rofekoksib avregistrert. Kun 0,5\% (921 pasienter) av de 160000 rofekoksibbrukerne hadde tidligere fătt glukosamin, men i løpet av de neste to årene var det 5\% (8 368 pasienter) av dem som måtte slutte med rofekoksib som fikk glukosamin. I 2005 fikk 6014 tidligere rofekoksibpasienter glukosamin, gjennomsnittlig i en mengde tilsvarende et forbruk i 5,2 måneder. Av disse fikk 3974 også midlet $i$ 2006, da gjennomsnittlig motsvarende 8,9 måneders forbruk. I mai 2005 ble celekoksib fjernet fra blåreseptordningen. Rundt hver tiende (11 544 pasienter) av de 104000 celekoksibpasientene fikk da skrevet ut glukosamin. I gjennomsnitt fikk de i 2006 glukosamin nok til 4,2 måneders forbruk.

\section{Forskrivers spesialitet}

Glukosaminreseptene var skrevet ut av 8881 forskjellige leger. Over halvparten (4 736) manglet oppnådd spesialitet, og disse sto for $34 \%$ av reseptene.

Av legene med spesialitet ordinerte $92 \%$ av alle allmennmedisinerne minst én glukosaminresept, og de startet behandlingen hos $51 \%$ av pasientene (tab 2). Totalt sto de for $84 \%$ av spesialistenes glukosaminordineringer.

\section{Storforbrukere og storforskrivere}

21 pasienter hadde fått mer enn én glukosaminresept i måneden (antall ordineringer > 36) i treårsperioden, mens gjennomsnittlig antall ordineringer per pasient $i$ treårsperioden var 3,3 (standarddeviasjon 3,2). En pa-

Tabell 2 Prosentvis andel av legespesialister som skrev ut minst én glukosaminresept i perioden 1.1. 2004-31.12. $2006 \mathrm{og}$ andelen pasienter som startet glukosaminbehandlingen hos ulike spesialister

\begin{tabular}{lcc} 
Forskrivers spesialitet & $\begin{array}{c}\text { Andel av spesialister (\%) } \\
\text { som ordinerte } \\
\text { glukosamin }\end{array}$ & $\begin{array}{c}\text { Andel pasienter (\%) } \\
\text { som fikk startet behandling } \\
\text { hos vedkommende spesialist }\end{array}$ \\
\hline Allmennmedisin & 92 & 51,0 \\
\hline Revmatologi & 64 & 5,1 \\
\hline Ortopedi & 42 & 4,3 \\
Fysikalsk medisin & 20 & 0,3 \\
\hline Indremedisin & 18 & 1,1 \\
\hline Psykiatri & 8 & 0,2
\end{tabular}

sient i 80-årene løste inn til sammen 67 glukosaminresepter på apoteket i løpet av 16 måneder, noe som tilsvarer gjennomsnittlig 7,5 DDD per dag. For dette betalte hun totalt 3521 kroner.

I gjennomsnitt skrev legene ut 33,3 glukosaminresepter hver (spredning 1-1 953), mediant antall resepter per lege var 11. Tre revmatologer skilte seg ut ved at de hadde skrevet ut til sammen 4646 glukosaminresepter (kostnad 1,4 millioner kroner). De initierte behandlingen hos 1339 pasienter, det vil si hos $28,8 \%$ av alle dem som fikk første resept fra en revmatolog.

\section{Diskusjon}

Økende bruk av glukosamin førte ikke til redusert forbruk av andre smertestillende midler. De som fikk mest glukosamin, fikk samtidig også signifikant mer NSAID-preparater. Avregistrering og tilbaketrekking av refusjon for enkelte koksiber førte midlertidig til økt bruk av glukosamin, men det typiske var at pasientene gikk over til et annet NSAID-preparat (20).

Økningen i antall pasienter som fikk glukosamin var forholdsvis mindre i $2006 \mathrm{enn}$ økningen fra 2004 til 2005. I 2007 falt salget med 4\% (20). Denne trenden kan dels reflektere metning i markedet, men like viktig er trolig økende tvil om glukosamin har noen klinisk effekt - etter publisering av negative forskningsresultater (12), som også ble kommentert under Medisinsk nytt i Tidsskriftet (21).

I den grad etterlevelse kan antas ut fra regelmessig innløsning av flere resepter over tid, er denne relativt god for glukosamin, siden en tredel av pasientene fortsatte med midlet $i$ tre år og halvparten i minst to år. Det er imidlertid uvisst om dette skyldes at pasientene opplevde smertelindring, hadde håp om at glukosaminbruk ville redusere brusknedbrytning over tid eller ikke var plaget av bivirkninger. På den annen side kan det faktum at $41 \%$ av pasientene ikke hentet mer enn én resept, tyde på manglende subjektivt opplevd effekt. Fordi alvorlige eller plagsomme glukosaminbivirkninger er uvanlig, er bivirkninger neppe en viktig årsak til seponering.
Spesialister i allmennmedisin, revmatologi og ortopedi skrev ut flest glukosaminresepter (tab 2), antakelig fordi de har flest artrosepasienter. Reseptregisteret mangler informasjon om hvilket fagområde en forskriver tilhører hvis vedkommende ikke er ferdig spesialist. Rutinemessig samkjøring med fastlegeregisteret hadde derfor vært ønskelig for å identifisere fastleger under utdanning til spesialiteten i allmennmedisin.

Undersøkelsen avdekket enkeltforskrivere som skilte seg klart ut fra gjennomsnittet. Det kan være grunn til å se nærmere på hvilke faktorer som gjør at noen er svært raske med å tilby nye legemidler, mens andre er mer tilbakeholdne.

\section{Konklusjon}

Mange artrosepasienter bruker glukosamin over lang tid og er villige til å betale for dette. En stor andel av dem som starter med midlet, avslutter imidlertid behandlingen etter kort tid. Hos dem som fortsetter, fører ikke glukosaminbruken til redusert bruk av andre smertestillende medikamenter, herunder NSAID-preparater. Dette styrker mistanken om at den kliniske effekten av glukosamin ved artrose er beskjeden - eller mangler helt.

Studien ble gjennomfort ved hjelp av allmennpraktikerstipend fra Allmennmedisinsk forskningsutvalg. Vi takker Magne Thoresen for statistiske råd.

Oppgitte interessekonflikter: Ingen

\section{Litteratur}

1. Lawrence RC, Helmick CG, Arnett FC et al. Estimates of the prevalence of arthritis and selected musculoskeletal disorders in the United States. Arthritis Rheum 1998; 41: 778-99.

2. Creamer P, Hochberg MC. Osteoarthritis. Lancet 1997; 350: $503-9$.

3. Felson DT. Osteoarthritis - new insights. Part 1 : the disease and its risk factors. Ann Intern Med 2000; 133: 637-9.

4. Spector TD, Cicuttini F, Baker J et al. Genetic influences in women: a twin study. BMJ 1996; 312 $940-3$

5. Moe RH, Haavardsholm EA, Christie A et al. Effectiveness of nonpharmacological and nonsurgical interventions for hip osteoarthritis: an umbrella review of high-quality systematic reviews. Phys Ther 2007: 87: 1716-27. 
6. Jamtvedt G, Dahm KT, Christie A et al. Physical therapy interventions for patients with osteoarthritis of the knee: an overview of systematic reviews. Phys Ther 2008; 88: 1-14.

7. Bjordal JM, Klovning A, Ljunggren AE et al. Shortterm efficacy of pharmacotherapeutic interventions in osteoarthritic knee pain: a meta-analysis of randomised placebo-controlled trials. Eur J Pain 2007; 11: 125-38.

8. Jordan KM, Arden NK, Doherty M et al. EULAR recommendations 2003: an evidence based approach to the management of knee osteoarthritis: report of a task force of the Standing Committee for International Clinical Studies Including Therapeutic Trials (ESCISIT). Ann Rheum Dis 2003; 62: $1145-55$.

9. Towheed TE, Maxwell L, Anastassiades TP et al. Glucosamine therapy for treating osteoarthritis. Cochrane Database Syst Rev 2005; nr. 2: CD002946.

10. Reginster JY, Deroisy R, Rovati LC et al. Long-term effects of glucosamine sulphate on osteoarthritis progression: a randomised, placebo-controlled clinical trial. Lancet 2001; 357: 251-6.

11. Pavelka K, Jindriska G, Olejarova M et al. Glucosamine sulfate use and delay of progression of knee osteoarthritis: a 3-year, randomized, placebo-controlled, double-blind study. Arch Intern Med 2002; 162: 2113-23.

12. Clegg DO, Reda DJ, Harris CL et al. Glucosamine, chondroitin sulfate, and the two in combination for painful knee osteoarthritis. N Engl J Med 2006; 354: 795-808

13. Sawitzke AD, Shi H, Finco MF et al. The effect of glucosamine and/or chondroitin sulfate on the progression of knee osteoarthritis. Arthritis Rheum 2008; 58: 3183-91.

14. Hoffer JL, Kaplan LN, Hamadeh MJ et al. Sulfate could mediate the therapeutic effect of glucosamine sulfate. Metabolism 2001; 50: 767-70.

15. Vlad S, La Valley MP, McAlindon TE et al. Glucosamine for pain in osteoarthritis: why do trial results differ? Arthritis Rheum 2007; 56: 2267-77.

16. Roland PDH, Bjordal JM, Klovning A et al. Glukosamin - den store sukkerpillebløffen. Tidsskr Nor Lægeforen 2007; 127: 2121-2.

17. Sundal E, Madsen S. Glukosamin - en oppdatering. Statens legemiddelverk 30.8.2007. www.legemiddelverket.no/templates/ InterPage_53492.aspx?filterBy=Copy ToMedecs (23.3.2010).

18. Vinge E. Glukosamin för lindring av besvär vid artros. Tidsskr Nor Lægeforen 2005; 12: 1667-8.

19. Furu K. Establishment of the nationwide Norwegian Prescription Database (NorPD) - new oppurtunities for research in pharmacoepidemiology in Norway. Norsk Epidemiologi 2008; 18: 129-36.

20. Rønning M, red. Legemiddelforbruket i Norge 2003-2007. Oslo: Nasjonalt folkehelseinstitutt, 2008.

21. Bretthauer M. Glukosamin har ingen effekt ved artrose. Tidsskr Nor Lægeforen 2006; 9: 1185.

Manuskriptet ble mottatt 13.1. 2009 og godkjent 14.5. 2010. Medisinsk redaktør Trine B. Haugen. 